\title{
CHANGES OF VISUAL FUNCTION AND VISUAL ABILITY IN DAILY LIFE FOLLOWING CATARACT SURGERY
}

\author{
Dagmar Hejcmanová ${ }^{1}$, Hana Langrová ${ }^{1}$, Lisa Bytton ${ }^{1}$, Markéta Hejcmanová ${ }^{2}$ \\ Charles University in Prague, Faculty of Medicine in Hradec Králové: Department of Ophtalmology ${ }^{1}$; University Hospital \\ Bohunice, Brno: Department of Ophtalmology ${ }^{2}$
}

\begin{abstract}
Summary: Purpose: To examine best corrected visual acuity (BCVA), contrast sensitivity (CS) and functional visual complaints in early cataract and after the cataract surgery. Patients and methods: 53 eyes with early cataract (BCVA 20/30: Snellen charts) were examined before the surgery as well as 12 months after the surgery. BCVA was tested using $\log M A R$ chart. CS was examined using VCTS chart in 6 spatial frequencies. Influence of glare was tested using BAT. Patients' subjective visual functions were evaluted using a questionnaire (distance vision, near vision, mesopic vision and glare conditions). 22 subjects were examined as control group. Results: BCVA was $0.52(0.22-1.05)$ preoperatively and 0.83 (0.37-1.26) postoperatively. BCVA in patients in both terms was significantly lower compared to the control group. CS in patients before surgery was significantly lower compared to controls, postoperatively improved significantly and was only nonsignificantly lower compared to controls except for the highest spatial frequency. Glare had only nonsignificant influence. The questionnaire scores were correlated with visual performance in both terms. Conclusions: The significant improvement of both BCVA and CS suggest that cataract surgery improves quality of life in early cataract. Questionnaire should be considered as adjuncts to BCVA and CS in evaluating early cataract.
\end{abstract}

Key words: Early cataract; LogMAR chart; Contrast sensitivity; Glare; Subjective visual complaints

\section{Introduction}

Cataract, opacification of the lens, is the ocular diagnosis the most frequently stated nowadays. With the increasing life expectancy of the population, an increasing need for performing cataract surgeries and implantations of artificial intraocular lens is expected. In the Czech Republic alone, 52.000 patients underwent a cataract surgery in 2002. Advances in cataract surgery have improved the ratio of risks to benefits and therefore the indications for cataract surgeries should be re-evaluated ${ }^{18}$.

A steadily improving operation technique allows successfully operating not only progredient but also early cataract stages when a visual acuity tested on Snellen charts can be detected only to a minimal extent or not at all. These patients retain good visual acuity but complain about visual problems. Patients with media opacities can be seriously disabled at some real world visual tasks (which can be detected by contrast sensitivity test) or under glare conditions. In spite of this fact, most ophthalmologists consider Snellen visual acuity equal to or better than $6 / 9$ as fully sufficient although it is known that evaluation of visual acuity by using $100 \%$ contrast informs us only about a part of spectrum of visual perception and does not provide any in- formation about visual functions under lower contrast conditions or increased glare ${ }^{5}$.

Visual acuity tested on Snellen charts has long served as a primary visual function test in cataract evaluation. It is also used as a tool for evaluating surgery results. However, this test alone can not reveal a satisfactory or disappointing outcome.

Cataracts imperfectly refract incoming light causing intraocular scatter that diminishes the contrast ${ }^{9}$. In the case of further opacification of the lens, the glare disability can grow as a result of the light scatter. This correlates with functional complaints of the patients, for example car driving at dusk/dawn, in fog but also on bright days (difficulties in unfamiliar environment, distance estimation problems, difficulties with oncoming headlights or recognizing traffic lights or road signs), difficult face recognition (Fig 1), difficulties watching TV (impossibility to read subtitles), reading an ordinary print in newspapers or instructions on medicine bottles. The patients' reported vision disability depends on the percentage of time they spend under low contrast and/or low illumination conditions such as reading, working under dim illumination and walking or driving at night, in fog or in heavy rain. At the same the patients complain about reduced vision on bright days ${ }^{5}$. 


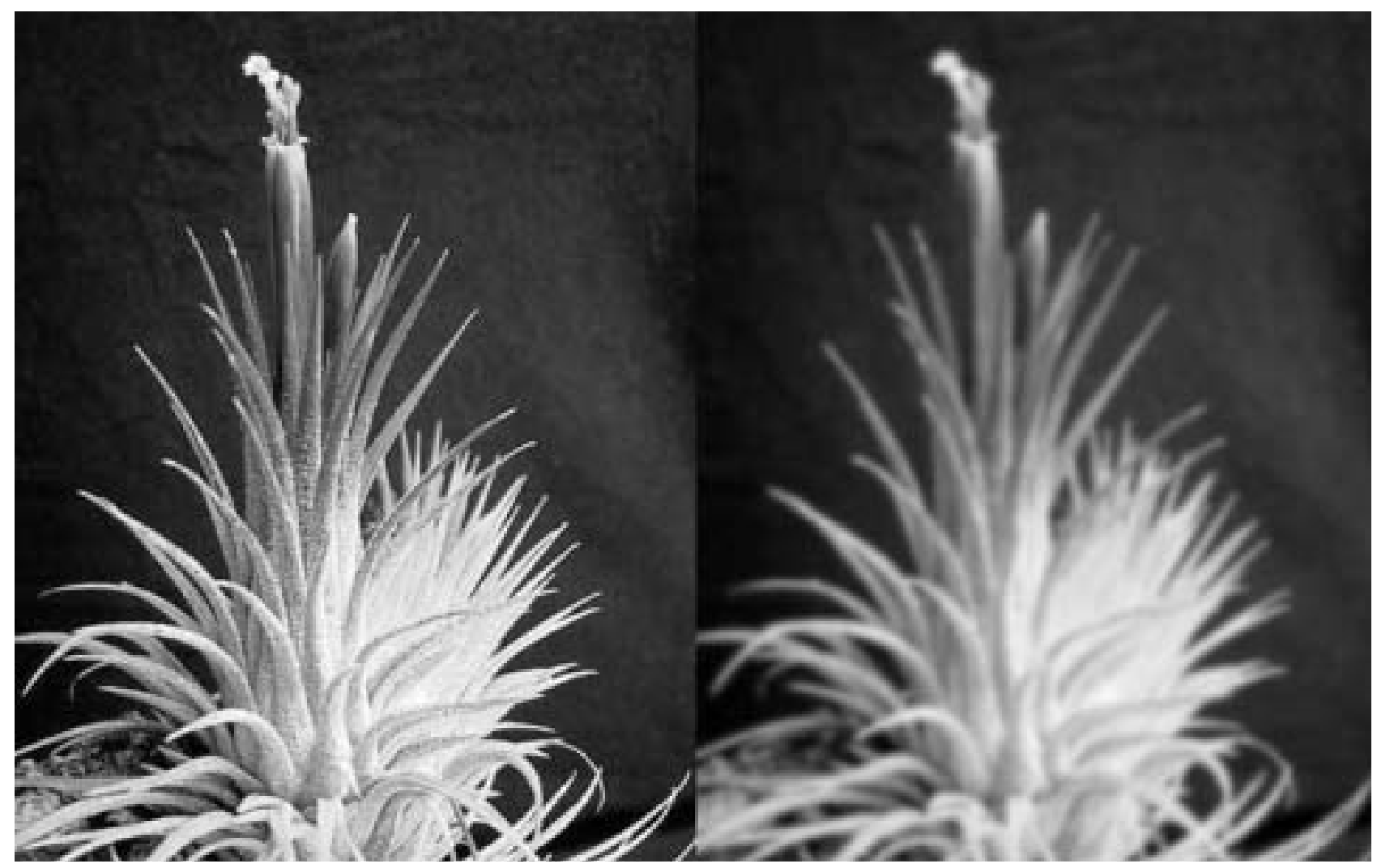

Fig. 1: Reduction of the object's contrast in cataract.

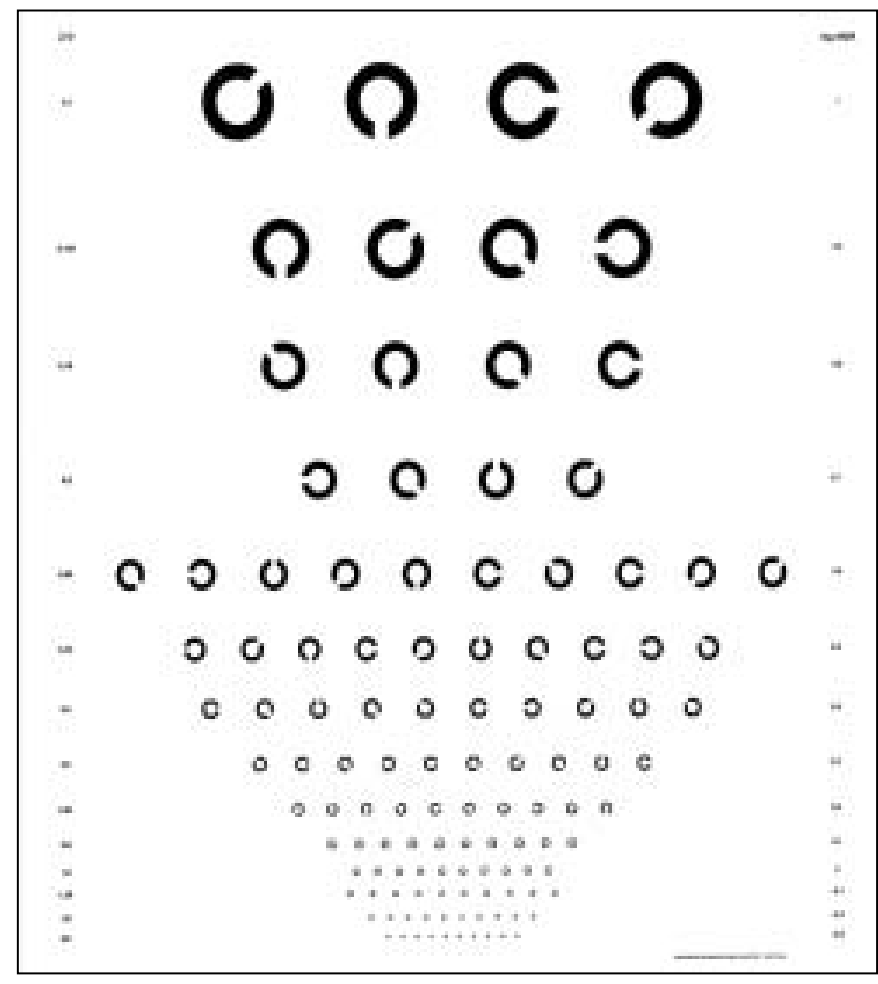

Fig. 2: LogMAR chart with Landolt rings.

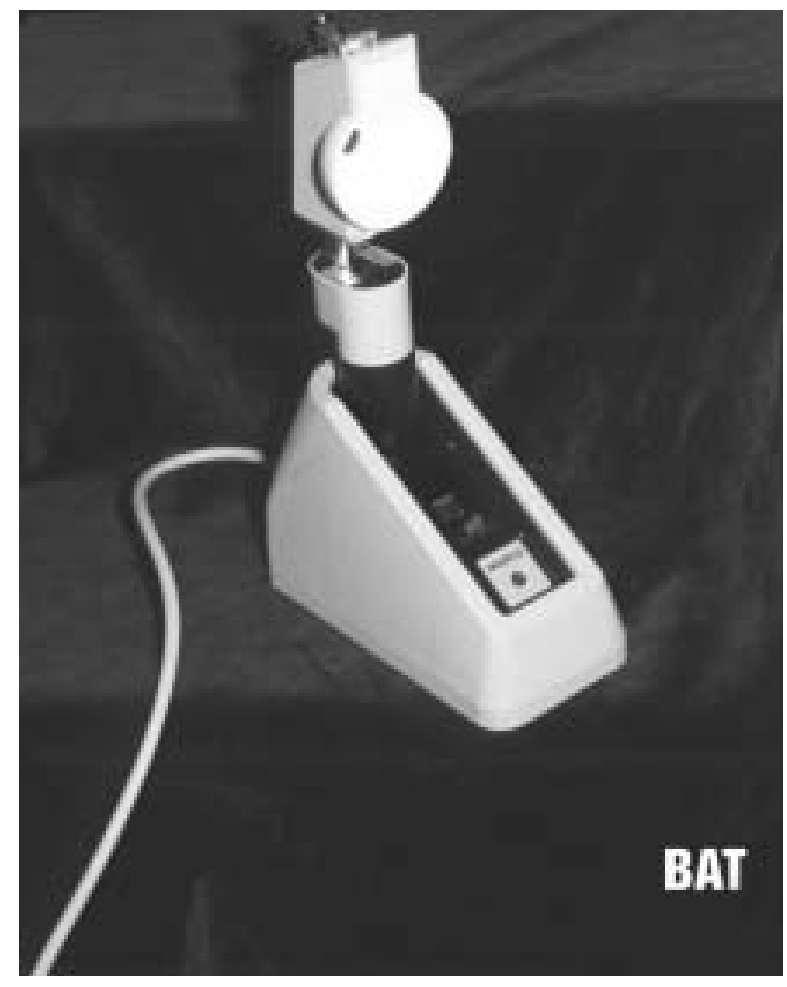

Fig. 3: Brightness Acuity Tester (BAT). 


\section{Purpose}

- to quantify incipient cataract patients' functional complaints prior to the surgery

- to observe visual functions of these patients during a 12-month-period after the surgery

- to determine to what extent the cataract surgery improves visual functions and whether this visual function improves the quality of life

- to determine whether the used tests can reveal visual problems of patients with incipient cataract

- to what extent these problems can change after the surgery

\section{Patients and Methods}

The study included an examination of 53 eyes of 53 patients with a mean age of 68 (range 37 to 93 years of age) with early cataract (best corrected visual acuity better than 6/9) preoperatively and 12 months postoperatively.

The control group for examination of visual acuity and contrast sensitivity included 22 eyes of 22 patients with a mean age of 61 (range 53 to 81 years of age) without any eye pathology with central visual acuity equal to $6 / 6$.

Best corrected visual acuity (BCVA) was measured under controlled lighting conditions using optotype logMAR charts. The distance for examination of threshold BCVA on $\log$ MAR charts was 4 meters. Each of 14 rows for visual acuity between $0.1(20 / 100)$ and $2.0(20 / 10)$ contained 10 Landolt rings. Their size in the subsequent rows grew with a logarithmic progression (Fig. 2).

Contrast sensitivity was tested using a Ginsburg's VCTS chart (Vistech Consultants, Dayton, USA), the distance for contrast sensitivity measurements was 2.08 and 4.2 meter and thus a range of spatial frequencies from 1.15 to 27.25 c/deg was achieved $(1.15 ; 1.96 ; 4.00 ; 7.97 ; 16.00 ; 27.25)$.

The glare disability was tested using the Brightness Acuity Tester (BAT) (Mentor, INC, Norwell, MA) (Fig. 3) which is a $60 \mathrm{~mm}$ diameter hemisphere with a diffusing surface that is placed in front of the eye. There is a $12 \mathrm{~mm}$ central hole through which a visual acuity is viewed. The visual acuity and contrast sensitivity were measured first without any glare illumination to obtain a baseline score and then with the glare light turned onto the medium setting $342 \mathrm{~cd} / \mathrm{m}^{2}$.

The patients with incipient cataract were asked to fill out a questionnaire in order to quantify their subjective visual impairment. The questionnaire focuses on evaluating visual difficulties in long distance, short distance, and under glare. 49 questionnaires were completed and evaluated retrospectively.

\section{Results}

Visual acuity

The average threshold visual acuity (logMAR) in patients with cataract measured pre-operatively on Landolt rings without glare has reached the value of 0.52 (range 0.22 to 1.05 ), with glare 0.53 (range 0.21 to 0.95 ). The values in both cases were significantly lower compared to measurements in the control group ( $\mathrm{p}<0.001)$. The glare does not influence the results of measurement.

The average visual acuity (logMAR) significantly improved at the 3-month-follow up, the improvement was about 2 lines and it stayed on the same level 12 months after the surgery: without glare 0.83 (range 0.37 to 1.26 ) with glare 0.85 (range 0.37 to 1.23 ). In comparison with the control group, the VA values are lower, but only on the level $\mathrm{p}<$ 0.05. The influence of glare was not proved (Fig. 4).

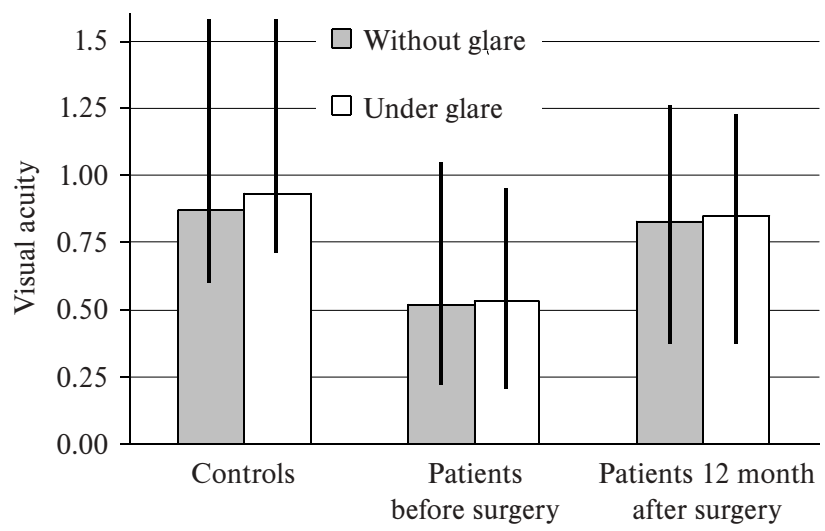

Fig. 4: Patients versus controls - visual acuity.

\section{Contrast sensitivity}

The preoperative results of contrast sensitivity show a significant reduction when compared with the control group ( $p<0.001$, with no influence of glare). The contrast sensitivity tested on VCTS chart improves at the 3-monthfollow up, and it differs significantly only at the highest frequencies at the 12 -month-follow up $(\mathrm{p}<0.01)$. Other values are significantly lower with regard to the control group.

Analogical results were obtained in measurements using the glare test, where the values are lower at all frequencies in comparison with the control group but only nonsignificantly $(\mathrm{p}<0.05)$ (Fig 5, Table 1).

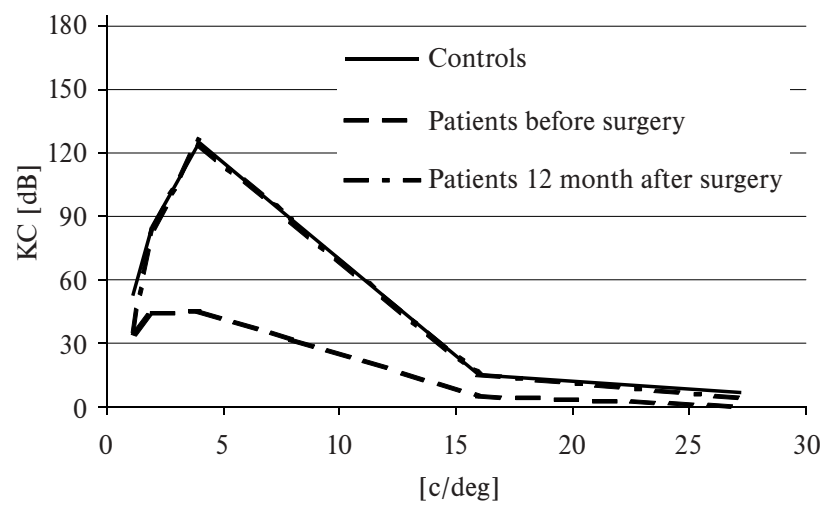

Fig. 5: Contrast sensitivity without glare using VCTS chart - patients and controls. 
Tab. 1: Contrast sensitivity without glare using VCTS chart - patients and controls.

\begin{tabular}{|l|r|r|r|r|r|r|}
\hline group c / deg & 1.2 & 2.0 & 4.0 & 8.0 & 16.0 & 27.3 \\
\hline Controls & 52.5 & 85.0 & 125.0 & 88.0 & 15.0 & 7.0 \\
\hline $\begin{array}{l}\text { Patients before } \\
\text { surgery }\end{array}$ & 35.0 & 44.0 & 45.0 & 32.0 & 5.0 & 0.0 \\
\hline $\begin{array}{l}\text { Patients 12 months } \\
\text { after surgery }\end{array}$ & 35.0 & 85.0 & 125.0 & 88.0 & 15.0 & 4.0 \\
\hline
\end{tabular}

Tab. 2: Subjective difficulties before surgery - after surgery.

\begin{tabular}{|l|c|c|}
\hline & $\begin{array}{c}\text { difficulties } \\
\text { before } \\
\text { surgery [\%] }\end{array}$ & $\begin{array}{c}\text { improvement } \\
\text { after } \\
\text { surgery [\%] }\end{array}$ \\
\hline work in the near & 49 & 71 \\
\hline watching TV & 45 & 65 \\
\hline $\begin{array}{l}\text { orientation in unknown } \\
\text { environment }\end{array}$ & 35 & 35 \\
\hline $\begin{array}{l}\text { distance estimation } \\
\text { in long distance }\end{array}$ & 49 & 90 \\
\hline $\begin{array}{l}\text { distance estimation } \\
\text { in short distance }\end{array}$ & 16 & 16 \\
\hline distincting of the faces & 39 & 64 \\
\hline $\begin{array}{l}\text { adaptation to the changes } \\
\text { of illumination }\end{array}$ & 35 & 41 \\
\hline $\begin{array}{l}\text { difficulties } \\
\text { with perception of color hues }\end{array}$ & 19 & 38 \\
\hline
\end{tabular}

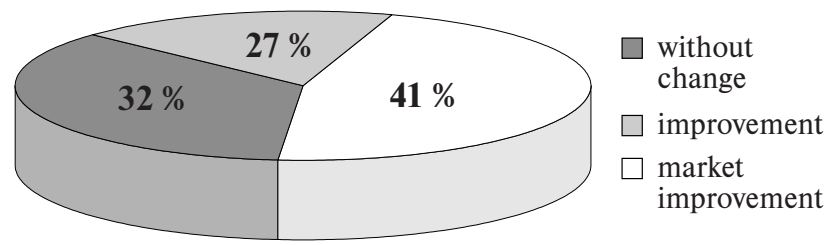

Fig. 6: Changes in everyday activity after surgery.

\section{Evaluation of functional complaints of patients with cataract} pre- and postoperatively with the help of a questionnaire

Visual problems of the same patients were quantified retrospectively with the help of 49 completed questionnaires. We are able to explain the visual problems with the help of visual acuity tests for long distances only in $45 \%$ of patients and for short distances in $49 \%$ of patients. Greater difficulties of the patients consist in inadequate distinction of bigger objects more so than in distinguishing details. Preoperatively, $35 \%$ of patients report difficulties while passing from daylight into the night and vice versa, $41 \%$ of patients realize an improvement after the surgery. Short distance estimation problems do not change after the operation. There is, however, a $90 \%$ postoperative improvement in long distance estimation in $49 \%$ of preoperative patients. In regards to the change of color hues perception, $19 \%$ of patients realize this change preoperatively, while after the surgery $38 \%$ of patients can feel a difference (Table 2). Finally, the question concerning everyday activities: improvement is shown postoperatively in $68 \%$ of patients over all, where significant improvement exists in $25 \%$ of patients and $32 \%$ of patients describe no change (Fig. 6).

\section{Discussion}

Our results after studying the patients with early cataract and visual acuity of $6 / 6$ or $6 / 9$ during the preoperative period show a significant visual acuity decrease on logMAR charts.

In the post-operative period, using the same method, we report visual acuity improvement of up to 2-3 standardized lines. The visual acuity (VA) tested on Snellen charts, however, stays on the level of $6 / 6$ just like in the pre-operative measurements. The results of this exact VA evaluation with the help of the logMAR charts demonstrate inaccurate measurements of VA, as Peregrin describes ${ }^{13}$. The measurement of the long distance short distance visual acuity alone does not have to reveal any changes in visual perception $^{12}$. It is the contrast sensitivity test which is more suitable for testing a suspicion of opacification of the lens clinically. This can detect contrast patients' visual problems under conditions of lower contrast as it is in some real world vision tasks ${ }^{11}$. Even in young patients, there is a scatter of 10 to $20 \%$ of light and this causes problems when distinguishing fine details at high contrast ${ }^{15}$. Any opacification of lens means a manifold increase in the amount of the light scatter and subsequent reduction in retinal image. Superposition of retinal image with scattered light causes a drop in contrast and thus blurred vision ${ }^{2}$.

Our study showed a decrease in contrast sensitivity at all spatial frequencies before surgery in comparison with the control group. Postoperatively, significant improvement of contrast sensitivity can be detected which stays on the same level during the following 12 months. Contrast sensitivity in our study measured by using Guinsburg's VCTS charts reached the same values measured in the control group, which corresponds to Skorkovska's findings ${ }^{16}$. Certain differences in comparison with the control group in the same age group can be explained by the optic quality of the artificial lens alone. The lenses tested in vitro are perfectly transparent and do not influence the contrast values. In spite of this, they can significantly worsen contrast sensitivity when inserted into an eye. Sommer et al. ${ }^{17}$ explains these unexpected results as disturbance of pupil reaction, pigment release during the operation, possible fibrosis of posterior capsule and its wrinkles, decentration of lens and potential discrete changes of retina structure.

The authors can not show any glare influence on the CS, unlike Superstein's findings ${ }^{18}$. The reason is probably a different spectrum of patients with middle opacification of lens with visual acuity of 20/70 or better where the glare influence on the CS is greater than in our group of patients 
with VA of 6/9-6/6. Martinová ${ }^{10}$ also detects analogical results in a group of 25 patients where only one patient states difficulties with glare and that is why Martinová ${ }^{10}$ only recommends this examination in the cases of mid-impaired vision or worse.

Superstein ${ }^{19}$ supposes that all objective tests are useful only if patient's functional complaints correspond with the results of objective measurements.

For this reason, one part of our study includes detection of subjective visual problems of patients before and after the surgery and their correlation with objective measurements with the help of a questionnaire. This questionnaire was adapted to the gender and the age of the patients in our group. We have chosen a simple, intelligible form with a focus on vision difficulties at work or at everyday tasks, particularly in lower contrasts in relation to 1) fine detail distinction (far and near), 2) distinction of larger objects at lower illumination, distance estimation and orientation in unfamiliar environment, 3) impaired vision on bright days, passing from night into day and vice versa, all compared to normal VA.

Our results show that patients become aware of pre- and postoperational changes in vision functions in spite of the fact that the preoperative measurement responded to standardized values (6/6-6/9). The short distance vision difficulties can be explained in $45 \%$ and the long distance vision difficulties in $49 \%$ of patients with the help of objective tests for evaluating visual acuity.

It was proved that patients have bigger problems to distinct larger objects than fine details. This is consistent with contrast sensitivity results that were significantly lower during the preoperative period and postoperatively increased particularly at intermediate spatial frequencies and lasted up to 12 months after the surgery. The decrease at intermediate spatial frequency is referred to as hidden loss of vision functions ${ }^{14}$.

At last, our study proved that $68 \%$ of patients reported improvement in their ability to cope with vision-dependent activities of everyday life, $41 \%$ of patients reported a significant improvement and $32 \%$ of patients reported the same state as before the surgery. These findings are similar to those of Bernth-Petersen ${ }^{3}$ where $69 \%$ of patients reported improvement in everyday activities and $86 \%$ of patients reported subjective improvement of their vision.

We agree with the statement of Chang-Godinich and $\mathrm{al}^{6}$. who claims that patients in a bad health condition and of the age of 75 and over expect more of the surgery than younger, healthy persons and than what their real health condition allows them to do in their everyday activities. For this reason, only a small percentage of patients were unsatisfied in spite of their excellent objectively measured visual functions. This group of patients should be properly informed of real possibilities of the postoperative result. On the other hand, the group of younger patients should be informed about a loss of the accommodation ability after the cataract surgery ${ }^{1}$.
Our study shows that surgery straightens out also difficulties in patients with a very incipient cataract. The risks of other changes or worsening of symptoms are very low. For the timing of the cataract surgery, it could be also helpful to evaluate subjective complaints of the patients. It is also necessary to explain the real state of things and the possible postoperative results to the older patients.

The CS test is a simple, fast, not very demanding method that can reveal certain subjective difficulties of patients particularly at dim illumination or in lower contrast conditions. The results can be influenced by many factors (illumination, age, various eye and general diseases). It is a supplementary nonspecific method. It can help us make subjective complaints of the patients with incipient cataract objective despite the good visual acuity tested on the Snellen charts. It enables a more exact evaluation of visual functions in everyday activities than what a mere test of central vision, using high contrast optotype charts, would yield.

\section{Conclusion}

Contrast sensitivity is no doubt a more sensitive method of examination of visual functions than testing visual acuity alone because it brings information about patients' vision at different contrast as it is in everyday life.

We proved an inaccuracy of measurements of visual acuity on the Snellen charts.

The individual results of measurement have to be always evaluated with the age factor in mind because there is a significant drop at intermediate and high spatial frequencies at a higher age ${ }^{4}$.

We have found out a significant correspondence between objective measurements of contrast sensitivity and subjective functional complaints of the patients before the surgery.

The visual functions and subjective visual problems have significantly improved postoperatively and the improvement has lasted up to 12 months after the surgery.

In our study, the influence of glare on the contrast sensitivity and visual acuity was not justified, most likely for reasons of minimal changes in the lens while it is the contrast sensitivity test which would be more sensitive.

The results of our measurements could be a helpful contribution to a discussion about the relevance of the indications for an early cataract surgery.

Supported by Grant of Grant agency of Czech Republic to HL No 309/00/D056

\section{References}

1. Abrahamsson M, Carlsson B,Törnqvist M, Sterner B. Changes of visual function and visual ability in daily life following cataract surgery. Acta Ophtalmolol Scand 1996;74:69-73.

2. Berg TJTP. Importance of pathological intraocular light scatter for visual disability. Doc Ophtalmol 1986;61:327-333.

3. Bernth-Petersen $P$ van den. The effectiveness of the cataract surgery, a retrospective study. Acta Ophtalmol (Copenh) 1981;59:50. 
4. Derefeldt G, Lennestrand G, Lundh B. Age variations in normal human contrast sensitivity. Acta Ophthalmol 1979;57:679-90.

5. Elliot BD, Bullimore MA, Patla AE, Whitaker D. Effect of cataract simulation on clinical and real world vision. Br J Opthalmol 1996;80:799-804.

6. Chang-Godinich A, Ou RJ, Koch DD. Functional improvement after phacoemulsification cataract surgery J Cat Refract Surg 1999;25:1226-31.

7. Langrová H, Hejcmanová D, Peregrin J. Jak určovat vizus? Čs Oftal 1996;52: 158-63.

8. Langrová H, Hejcmanová D, Peregrin J, Feuermannová A, Rozsíval P. Porovnán zrakových funkcí u myopie nad -6,0 dpt po fotorefraktivní keratektomii a laser in situ keratomileusis. Cs Oftal 2001;57:298-303.

9. Lasa MSM, Datiles III MB, Podgor MJ et al. Contrast and glare sensitivity. Ophtalmology 1992;99:1045-9.

10. Martin L. Computarized method to measure glare and contrast sensitivity in cataract patients. J Cat Refract Surg 1999;25:411-5.

11. Nadler MP, Miller, D, Nadler DJ. Glare and contrast sensitivity for clinicians. In: Mannis, MJ, Zadnik K, Johnson, CA. Contrast sensitivity: A viewpoint for clinicians, Springer Verlag, New York Inc,1990;1-4.

12. Peregrin J, Hejcmanová D, Svěrák J. Kontrastová citlivost a vizus. Čs Ofta 1992;48:397-440

13. Peregrin J, Hejcmanová D, Kalinová N, Svěrák J. Česká státní norma pro určování vizu. Čs Oftal 1999;55:48

14. Peregrin J, Svěrák J, Hartmann M, Hejcmanová D, Novák I. Citlivost na kontrast u člověka. Čs Oftal 1988;44:389-99.

15. Regan D, Glaschi DE, Fresco BB. Measurement of glare susceptibility using lowcontrast letter charts. Optom Vis Sci 1993;70:969-75.
16. Skorkovská Š, Mašková Z, Synek S. Vliv operace katarakty na funkci kontrastové citlivosti. Ces a slov Oftal 2001;57:99-103.

17. Sommer E, Zehe A, Marré E. Bestimmung der kontrastempfindlichkeit bei Patienten mit Hinterkammerlinsen. Folia Ophtalmol 1991;16:94-6.

18. Superstein R, Boyaner D, Overbury O, Collins Ch. Glare disability and contras sensitivity before and after cataract surgery. J Cat Refract Surg 1997:23:248-53.

19. Superstein R, Boyaner D, Overbury O. Funtional complaints, visual acuity, spatial contrast sensitivity, and glare disability in preoperative and postoperative cataract patients J Cat Refract Surg 1999;25:575-81.

Submitted May 2003.

Accepted August 2003.

Doc. MUDr. Dagmar Hejcmanová, CSc., Charles University in Prague, Faculty of Medicine in Hradec Králové, Department of Ophtalmology, Sokolská 158, 50005 Hradec Králové, Czech Republic. e-mail: hejcmanovad@lfhk.cuni.cz 